\title{
Degradation of phenol and chlorophenols by mixed and pure cultures
}

\author{
SE Murialdo, R Fenoglio, PM Haure and JF González* \\ Facultad de Ingeniería, Juan B. Justo 4302 - B7608FDQ Mar del Plata - Argentina
}

\begin{abstract}
The enrichment of mixed cultures for species capable of degrading phenol and chlorophenols, as well as the isolation of pure cultures are investigated. The cultures obtained are capable of degrading phenol and chlorophenols (pentachlorophenol 2,3,5,6 tetrachlorophenol and 2,4,6 trichlorophenol) but not 2,4,5 trichlorophenol. The results suggest the feasibility of the use of toxic chemicals as phenols, hexadecane and other chlorophenols as co-substrates in field decontamination processes. The inhibitory effect of PCP is shown, and the influence of a readily degradable ancillary carbon source on the performance of pure cultures is reported, as well as the preliminary identification of the bacteria that showed higher PCP degrading activity.
\end{abstract}

Keywords: phenol degradation, chlorophenols, biodegradation

\section{Introduction}

Chlorophenols and phenols are introduced in the environment in the waste streams of several industrial operations, through its use as biocides or as by-products of other industrial operations, such as pulp bleaching with chlorine, water disinfection or even waste incineration. Chlorophenols and phenols have also been used as general purpose disinfectants, and it has been found that they can also appear as degradation products of other chlorinated xenobiotics (Bollag. et al., 1986). Because of their toxic effects, phenol and chlorophenols tend to accumulate and in some cases the contamination of soil and water is of concern (Keither and Tellard, 1979, Moos et al., 1983; Borthwick and Schimmel, 1978).

Several decontamination techniques are available for the removal of contaminants from water, although not all (such as adsorption or ion exchange) actually destroy the contaminant. Some techniques, such as incineration have recently come under heavy criticism. Although not exempt from potential implementation problems, biodegradation is a technique which could potentially degrade these contaminants to innocuous products (mainly $\mathrm{CO}_{2}$ and $\mathrm{H}_{2} \mathrm{O}$; also $\mathrm{Cl}^{-}$ in the case of chlorinated phenols). Microbial and fungi degradation of phenol and chlorophenols have been reported by several groups (Baker et al., 1980; Pignatelloet al., 1983; Saber and Crawford, 1985; Rozich and Colvin, 1986; Apajalahti and Salkinoja-Salonen, 1986; Radehaus and Schmidt, 1992; Ramos et al., 1995; Haggblom and Valo, 1995; McBain et al., 1995; Colores et al., 1995. Lee et al., 1998; Toumela et al., 1999; Reddy and Gold, 2000; Cortés et al., 2002). Other works are reported on chlorophenol degradation by mixed cultures (Kirsch and Etzel, 1973; Liu et al., 1981; Klecka and Maier, 1985, Puhakka et al., 1995). Although PCP degrading activity is in some cases higher when using pure cultures, the ability of mixed cultures to survive in a non-sterile environment is a key issue in field applications of biodegradation. A potential problem regarding PCPdegrading bacteria in soil is the high concentrations of $\mathrm{PCP}$ at some

\footnotetext{
* To whom all correspondence should be addressed.

巡+54223 481-6600; fax: +54223 481-0046; e-mail: froilan@ fi.mdp.edu.ar Received 24 October 2001; accepted in revised form 18 June 2003.
}

contaminated soil sites, where PCP concentrations as high as 9000 $\mathrm{mg} \cdot \mathrm{kg}^{-1}$ have been reported. An effective bacterial inoculum needs to tolerate high levels of $\mathrm{PCP}$ while maintaining a level of activity to provide efficient mineralisation (Shaw et al., 1997). The addition of organic substrates stimulates the dechlorination of chloroaromatic compounds (Hendriksen et al., 1992). Therefore the purpose of this report is to describe the effect of the presence of nontoxic organic compounds as glucose on the biodegradation of pentachlorophenol. Investigations concerned with pentachlorophenol removal pattern performed on the toxic waste components phenol, chloropehnols and hexadecane were also conducted since inevitably toxic components will be found in mixtures with nontoxic, or conventional wastes (Rozich and Colvin, 1986).

We report on our work on the enrichment of mixed cultures capable of degrading phenols and chlorophenols, usually the most recalcitrant (Neilson et al., 1985; Sittig, 1981) and introduce steps for the isolation of pure cultures and their preliminary identification.

\section{Materials and methods}

\section{Chemicals and reagents}

Pentachlorophenol (PCP 99\% pure) was obtained from Sigma Chemical Co. (St. Louis MO 63178 USA). Phenol and all chlorophenols were of the highest purity available from Aldrich Chemical Co. (Milwaukee, WI). All other chemicals used were of the highest purity available commercially.

\section{Culture conditions and media}

Samples were collected using non-sterile procedures from soil with a history of phenol contamination, wood chunks that had been exposed to formol and chlorophenol solutions, and soil containing pentachlorophenol near a wastewater discharge site. All enrichments were done in a mineral salts medium (MS base) containing (in grams of ingredient per liter): $\mathrm{NaNO}_{3}, 0.5 ; \mathrm{K}_{2} \mathrm{HPO}_{4}, 0.65 ; \mathrm{KH}_{2} \mathrm{PO}_{4}, 0.17$; and $\mathrm{MgSO}_{4}, 0.1$. The mineral salts (MS) medium for the lower buffer PCP medium, usually used for the incubation of PCP-degrading 
strains (Haggblom and Valo, 1995) was composed of $\left(\left.\mathrm{g} \cdot\right|^{-1}\right)$ : $\mathrm{K}_{2} \mathrm{HPO} 4$, $0.065 ; \mathrm{KH}_{2} \mathrm{PO}_{4}, 0.017 ; \mathrm{MgSO}_{4} .7 \mathrm{H}_{2} \mathrm{O}, 0.1 ; \mathrm{NaNO}_{3}, 1$, and bromothymol blue, $20 \mathrm{mg} \cdot \mathrm{I}^{-1}$, as a $\mathrm{pH}$ indicator. PCP was first converted to its sodium salt by dissolving it in $0.2 \mathrm{~N} \mathrm{NaOH}$ and then it was added directly to the MS medium as sodium pentachlorophenate at $5 \mathrm{mg} \cdot \mathrm{I}^{-1}$ in $250 \mathrm{ml}$ Erlenmeyer flasks. The final $\mathrm{pH}$ was adjusted to 7.3 (Stanlake and Finn, 1982). Wet unsieved soil (1 to $5 \mathrm{~g}$ ) from a PCP contaminated site was inoculated into $50 \mathrm{ml}$ of PCP-MS medium in $250 \mathrm{ml}$ Erlenmeyer flasks containing $5 \mathrm{mg} \cdot \mathrm{I}^{-1} \mathrm{PCP}$. The cultures were placed on a shaker $\left(120 \mathrm{r} \cdot \mathrm{min}^{-1}\right)$ for $30 \mathrm{~d}$ at $30^{\circ} \mathrm{C}$. This step served two purposes: to remove bacteria from particle surfaces and to induce PCP-degradative enzymes. Cultures were centrifuged at $2000 \mathrm{r} \cdot \mathrm{min}^{-1}$ for $10 \mathrm{~min}$ to remove particulate matter, and $5 \mathrm{ml}$ of each supernatant solution served to inoculate the same medium contained in simple, replacement medium batch cultures (Saber and Crawford, 1985). An aliquot (10\% v/v) of each supernatant fluid of culture solution was inoculated into $25,50,100,200,\left.500 \mathrm{mg} \cdot\right|^{-1}$ PCP-MS batch Erlenmeyer flasks for acclimation to increasing concentration of PCP. An equal volume of $0.2 \mathrm{M} \mathrm{NaOH}$ was added to small samples of culture medium immediately after the sampling and centrifuged at $2000 \mathrm{xg}$ for $15 \mathrm{~min}$. The absorbance of the clear supernatant produced was then read at $320 \mathrm{~nm}$ (the absorbance peak of PCP at the cultivation conditions) vs. a distilled water blank in $1 \mathrm{~cm}$ cells with a UV-visible spectrophotometer (UV-1601 PC Shimadzu) to calculate de PCP content (Saber and Crawford, 1985). In experiments in which sodium azide was added, correction for the azide absorption was made when calculating PCP content. Studies not described here, indicated less than 2\% adsorption of PCP to microbial cells (Saber and Crawford, 1985). When the PCP content of the $500 \mathrm{mg} \cdot \mathrm{I}^{-1} \mathrm{PCP}-\mathrm{MS}$ batch Erlenmeyer flask decreased to 1 to $2 \mathrm{mg} \cdot \mathrm{I}^{-1}, 45 \mathrm{ml}$ of the spent medium was removed from the flask leaving only $5 \mathrm{ml}$ as inoculum. Additional PCP-MS medium was added to bring the PCP content of the medium back up to 50 to 100 $\mathrm{mg} \cdot \mathrm{I}^{-1}$. This was called the replenishments medium method. The procedure was repeated throughout and this PCP-MS batch Erlenmeyer flask medium was used as inoculum for all experiments with phenol and chlorophenols due to the requirement for induction of the degradative enzymes (Shaw et al., 1997).

Flasks with media containing other chlorophenols or phenol were prepared with the same media and treatment as the PCP-MS batch Erlenmeyer flask plus the corresponding concentration of the compound being studied for degradation. The concentration of each compound was measured spectrophotometrically at its corresponding absorbance peaks: Phenol, $269 \mathrm{~nm} ; 2,4,6 \mathrm{TCP}, 312 \mathrm{~nm}$; 2,3,5,6 TeCP, $308 \mathrm{~nm} ; 2,4,5 \mathrm{TCP}, 310 \mathrm{~nm}$ (Drahonovsky and Vacek, 1971). Phenol and chlorophenols content were determined spectrophotometrically and compared with an standard curve (PCPAbs $=1$ correspond to $\left.50 \mathrm{mg} \cdot\right|^{-1}$; Phenol $\mathrm{Abs}_{269}=1$ correspond to 71 $\mathrm{mg} \cdot \mathrm{I}^{-1} ; 2,4,6 \mathrm{TCP} \mathrm{A}_{312}=1$ correspond to $50 \mathrm{mg} \cdot \mathrm{I}^{-1} ; 2,3,5,6 \mathrm{TeCP}$ $\mathrm{Abs}_{308}=1$ correspond to $43 \mathrm{mg} \cdot \mathrm{I}^{-1}$ and $2,4,5 \mathrm{TCP} \mathrm{Abs}_{310}=1$ correspond to $\left.\left.125 \mathrm{mg} \cdot\right|^{-1}\right)$. The flasks were kept at $25^{\circ} \mathrm{C}$ in the dark to avoid photo-decomposition of PCP. In each experiment an uninoculated flask was run as control for PCP volatilisation (Radehaus and Schmidt, 1992). All yield measurements were done twice in duplicate. Results are means $\pm \operatorname{SD}(n=3)$.

\section{Isolation of pure colonies}

Portions from PCP-MS batch Erlenmeyer flask medium were removed during PCP decreasing, diluted and surface plated on LB (Luria-Bertani) broth containing $25 \mathrm{mg} \cdot \mathrm{I}^{-1} \mathrm{PCP}$ solidified with $1.5 \%$ agar. Each colony was transferred four to seven times on LB broth containing $25 \mathrm{mg} \cdot \mathrm{I}^{-1} \mathrm{PCP}$ solidified with $1.5 \%$ agar and inoculated into standard test tubes (18 by $150 \mathrm{~mm}$ ) with $2 \mathrm{ml} \mathrm{D}$-glucose low buffer PCP medium. This medium contained $50 \mathrm{mg} \cdot \mathrm{I}^{-1} \mathrm{PCP}, 1 \%$ (w/v) D-glucose and $20 \mathrm{mg} \cdot \mathrm{I}^{-1}$ bromothymol blue. The standard test tubes with $2 \mathrm{ml}$ D-glucose low buffer PCP medium were placed on a shaker $\left(120 \mathrm{r} \cdot \mathrm{min}^{-1}\right)$ on a slant for aeration and were incubated for one week at $25^{\circ} \mathrm{C}$. An uninoculated tube, a tube inoculated with E. coli $251: 199$ and another with $P$. fluorescens 184 served as controls. Colonies whose colour turned yellow due to $\mathrm{HCl}$ release were restreaked onto $1.5 \%$ PCP-MS agar medium. The plates were incubated at $25^{\circ} \mathrm{C}$ and tested for PCP degrading capability in PCPMS batch cultures and for culture purity. Examination of PCP mineralisation abilities served to narrow the number of strains to be used in further studies.

The isolated strains were inoculated in MS solution containing $1 \%$ glucose, $\left.100 \mathrm{mg} \cdot\right|^{-1} \mathrm{PCP}$ and $15 \%$ glycerol, maintained in a deep freeze $\left(-80^{\circ} \mathrm{C}\right)$ and subcultured in PCP-MS medium for each experiment. Acclimated cells in PCP-MS liquid medium containing 25 to $500 \mathrm{mg} \cdot \mathrm{I}^{-1} \mathrm{PCP}$ were used as the inoculum for all PCP degradation experiments. All batch culture experiments were carried out in $250 \mathrm{ml}$ Erlenmeyer flasks filled with $50 \mathrm{ml}$ of PCP-MS medium, attached to a shaker $\left(120 \mathrm{r} \cdot \mathrm{min}^{-1}\right)$ at $25^{\circ} \mathrm{C}($ Lee et al., 1998).

The effects of glucose additions on PCP degradationwas tested. The mineralisation of PCP was monitored by measuring the absorbance at $320 \mathrm{~nm}$, and D-glucose by Glicemia enzimática (Wiener Laboratories S.A.I.C. Argentina) in a PCP-glucose batch culture. D-glucose was used at a concentration of 0.5 and $1 \%$ (w/v). Cell growth was measured as $\mathrm{CFU} / \mathrm{ml}$ (colony forming units per $\mathrm{ml}$ ) and absorbance at $600 \mathrm{~nm}$. When the PCP content of the PCPMS batch Erlenmeyer flask decreased to 1 to $2 \mathrm{mg} \cdot \mathrm{I}^{-1}, 45 \mathrm{ml}$ of the spent medium was removed from the flask, leaving only $5 \mathrm{ml}$ as inoculum, and additional PCP-MS medium without glucose was added to restore the PCP content of the medium to 50 to $100 \mathrm{mg} \cdot \mathrm{I}^{-1}$. After a period of time, replenishments were done with PCP-MS medium plus glucose in the same way as mentioned in the previous section. Another assay was done with hexadecane $(1 \%$ $\mathrm{v} / \mathrm{v}$ ) in the $250 \mathrm{ml} \mathrm{PCP-MS}$ batch Erlenmeyer flask. The flasks were kept in the dark to avoid photo-decomposition of PCP and uninoculated flasks were run in each experiment as controls for PCP volatilisation (Radehaus and Schmidt, 1992). All yield measurements were done twice in duplicate. Results are means $\pm \operatorname{SD}(n=3)$.

\section{Effect of azide}

One set of PCP-MS flasks containing $40 \mathrm{mg} \cdot \mathrm{I}^{-1}$ of PCP was inoculated with the mixed culture and incubated for $24 \mathrm{~h}$ before the addition of $0.02 \%(\mathrm{w} / \mathrm{v})$ sodium azide. Another set of flasks contained PCP, mixed culture and azide from the start while others contained PCP plus cells without azide. Control flasks contained azide plus PCP without cells. An uninoculated flask without azide were used as control for PCP volatilisation. All yield measurements were done twice in duplicate. Results are means $\pm \mathrm{SD}(n=3)$.

\section{Preliminary identification}

Colony morphology was tested and the fatty acid methyl esters (FAMEx) were analysed by gas chromatography (Model 5890 A. Hewlett-Packard) with a methyl phenyl silicone fused silica capillary column (Hp 19091 B-102). The FAME profile was obtained by microbial identification system software (Microbial ID, DE, USA). Results with similarity indices served as the measure of how well the strain matched a specific library entry. Similarity indices are in Euclidean Distance and to interpret Euclidean Distance, the following guidelines were used: 
- $\quad 0.500$ or higher - excellent match to subspecies/pathovar level

- 0.200 to 0.500 - good match to species level, pathovar or subspecies may not be reliable.

- $\quad 0.000$ to 0.200 - good match to genus, species is not reliable.

\section{Specific rate of PCP degradation}

In order to know how $\mathrm{mg} \cdot \mathrm{I}^{-1}$ of PCP was degraded for each CFU, the specific rate of PCP degradation was calculated as:

$$
\frac{(\partial \mathrm{PCP} / \partial \mathrm{t})}{\mathrm{CFU}}
$$

where:

$\mathrm{PCP}$ is the concentration of PCP in $\mathrm{mg} \cdot \mathrm{l}^{-1}$

$\mathrm{CFU}$ (colony forming units per $\mathrm{ml}$ )

$t$ is time in $\mathrm{h}$.

\section{Chloride estimation}

Chloride in culture filtrates was determined by $4500-\mathrm{Cl}^{-} \mathrm{B}$ argentometric method of the Standard Methods (Franson, 1988). Values shown for PCP and chloride concentrations are the means of duplicate determinations.

\section{Results and discussion}

\section{Mixed culture experiments}

A PCP-degrading population was initially established in media containing from 65 to $85 \mathrm{mg} \cdot \mathrm{I}^{-1} \mathrm{PCP}$ as sole source of carbon and energy (Fig. 1). Due to the low biomass resulting from growth on PCP as sole carbon source (Fig. 9), PCP degradation was assessed by measuring the loss of absorbance at $320 \mathrm{~nm}$, rather than by an increase in cell density. The mixed culture isolated from soil is capable of degrading PCP at different rates according to increasing concentration (up to $500 \mathrm{mg} \cdot \mathrm{I}^{-1}$ ) (Fig.10). From this mixed population, we have recently isolated one strain capable of degrading superhigh concentrations of PCP (up to $5000 \mathrm{mg} \cdot \mathrm{I}^{-1}$ ), higher than in any previous reports (data will be provided in a next edition). Also, the mixed population is capable of degrading repeatedly PCP in batch cultures, even after several medium replenishments (Fig. 1). This strongly suggests the complete degradation of PCP without the accumulation of inhibitory or toxic metabolites for this microorganisms. This is considered to be a very important issue to take into account in reactor processes. The same culture is also capable of degrading repeatedly 2,3,5,6 tetrachlorophenol (2,3,5,6 TCP) after several medium replenishments, but not $2,4,5$ trichlorophenol $(2,4,5$, TCP) (Fig. 2).

The mixed population is capable of degrading phenol solutions of up to $250 \mathrm{mg} \cdot \mathrm{I}^{-1}$ and 2,4,6 trichlorophenol (Fig. 7). Although the toxicity of chlorinated phenols tends to increase with the degree of chlorination, the results with 2,4,5 TCP are not surprising either, since chlorophenols having 2,4- or 2,6 chloro-substitution patterns were better substrates than 3,5-substituted chlorophenols. Similar patterns of chlorophenol degradation in which preferred degradation occurs for 2,6-substituted phenols have been observed with cells of strain KC-3 (Chu and Kirsch, 1973) and Flavobacterium sp. ATCC 39723 (Steiert et al. 1987), and with cell extracts from Arthrobacter sp. ATCC 33790 (Schenk et al., 1989). The observation that 2,4-DCP is degraded by strain SR3 but not by Flavobacterium sp. ATCC 39723 cells (Steiertet al. 1987) or Arthrobacter sp. ATCC 33790 cell extracts (Schenk et al. 1989), may indicate differences in substrate specificity, toxicity, or transport among these strains (Resnick and

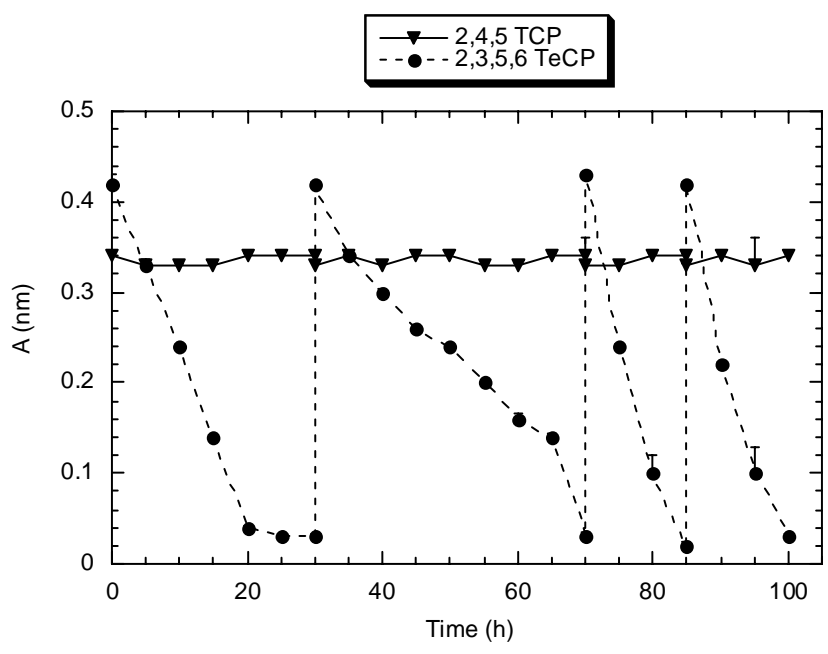

Figure 1

PCP degradation by the enriched mixed culture after several media replenishments (PCPAbs ${ }_{320}=1$ correspond to $\left.50 \mathrm{mg} \cdot \mathrm{I}^{-1}\right)$. Replenishments were made at each peak.

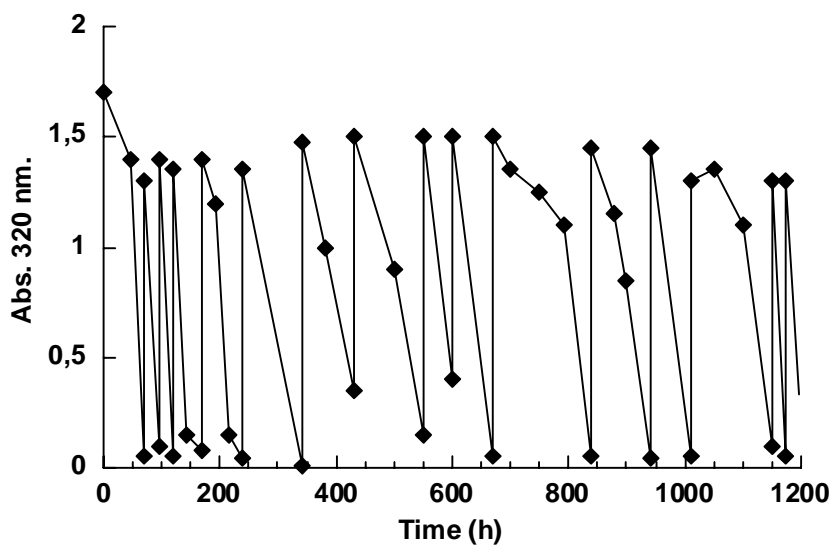

Figure 2

2,3,5,6 TeCP degradation and persistence of 2,4,5, TCP. Absorbance was recorded at their respective peaks (2,4,5 TCP, $O D_{310 \mathrm{~nm}}$ and 2,3,5,6 TeCP, $\left.O D_{308 \mathrm{~nm}}\right)$. 2,3,5,6 TeCP Abs $\mathrm{s}_{308}=1$ correspond to $43 \mathrm{mg} \cdot \mathrm{l}^{-1}$ and 2,4,5 TCP Abs ${ }_{310}=1$ correspond to $125 \mathrm{mg} \cdot \mathrm{l}^{-1}$. Symbols: $\mathbf{\nabla}, 2,4,5$, TCP concentration; $\bullet$ I, 2,3,5,6 TeCP concentration. Replenishments were made at each peak.

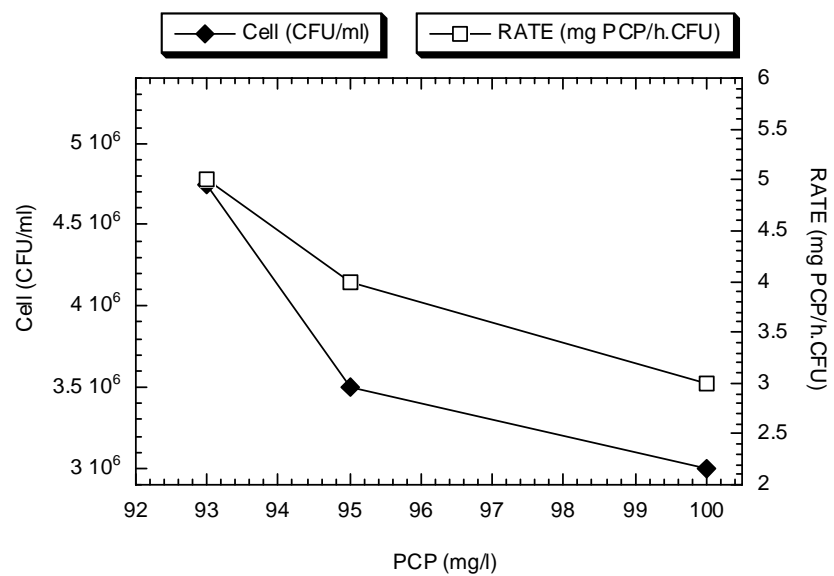

Figure 3

Decrease of specific degradation rate with increasing concentrations of PCP.

Symbols: , CFU/mI (CFU: colony forming units); $\square$, Specific degradation rate. 


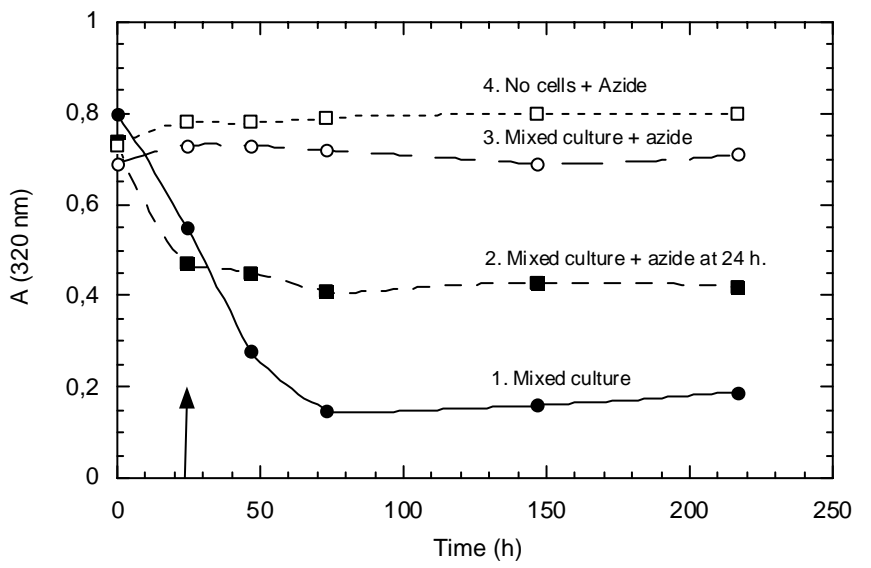

Figure 4

Indication that PCP degradation proceeds only with viable cells (PCPAbs ${ }_{320}=1$ correspond to $50 \mathrm{mg} \cdot \mathrm{I}^{-1}$ ). The arrow indicates the time of addtion of azide to flask 2.

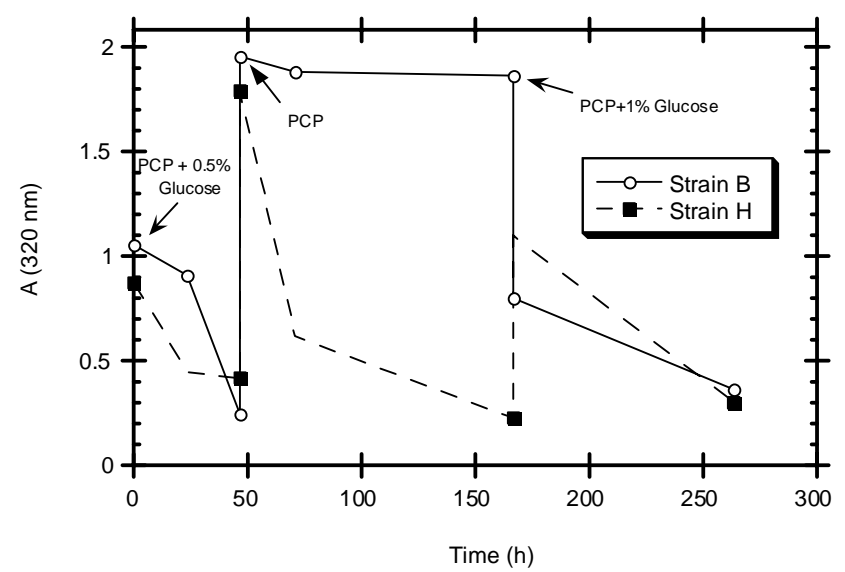

Figure 5

Effect of addtion of glucose on the degradation of PCP. $\left(P C P A b s_{320}=1\right.$ correspond to $\left.50 \mathrm{mg} \cdot \mathrm{l}^{-1}\right)$. The arrows indicate the time of addition of the indicated carbon sources.

Dashed lines correspond to strain $\mathrm{H}$, continuous lines correspond to strain $B$.

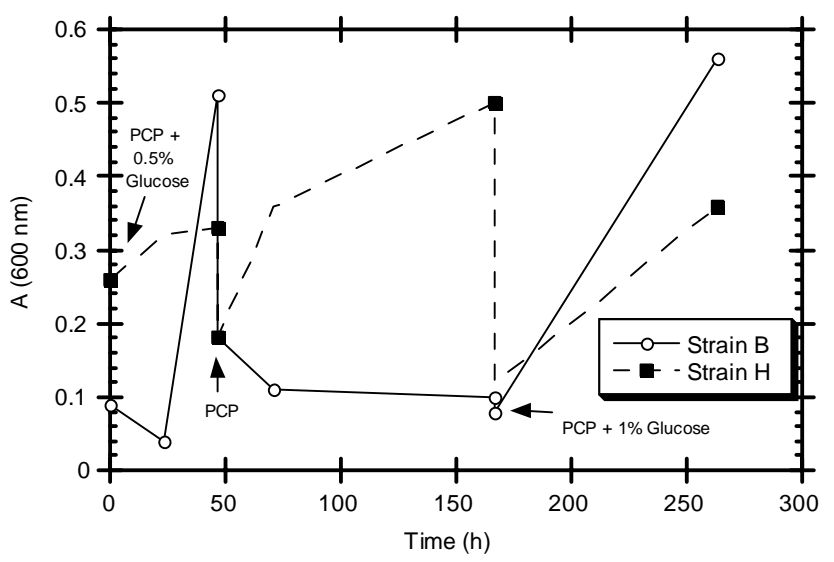

Figure 6

Effect of the addition of glucose on the growth of strains $B$ and $H$ in the presence of PCP. The arrows indicate the time ofaddition of the indicated carbon sources. Dashed lines correspond to strain $H$, continuous lines correspond to strain $B$.

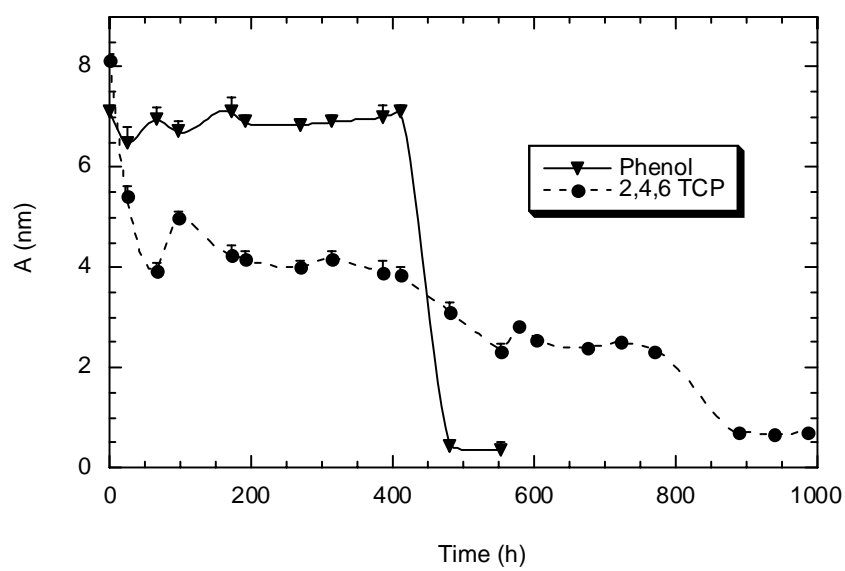

Figure 7

Phenol and 2,4,6 TCP degradation by the mixed culture. Continuous lines correspond to phenol concentrations measured at $286 \mathrm{~nm}$ (Phenol Abs $_{269}=1$ correspond to $71 \mathrm{mg} \cdot \mathrm{l}^{-1}$ ) and dashed lines correspond to 2,4,6 TCP concentrations measured at $312 \mathrm{~nm}\left(2,4,6\right.$ TCP $A_{312}=1$ correspond to $\left.50 \mathrm{mg} \cdot \mathrm{l}^{-1}\right)$ in batch MS medium.

Chapman, 1994). Steiert et al. (1988) showed that for a Flavobacterium sp. the $3,4,5 \mathrm{TCP}$ acts as an uncoupler of the oxidative phosphorylation, in the same way that PCP uncouples the same process in E. coli.

Approximately $49 \%\left(245 \mathrm{mg} \cdot \mathrm{I}^{-1}\right)$ of the influent PCP was removed $48 \mathrm{~h}$ after PCP was added to the PCP-MS batch Erlenmeyer flasks supplemented with $0.5 \%$ (w/v) glucose (Fig. 9), $22.8 \%$ $\left(\left.114 \mathrm{mg} \cdot\right|^{-1}\right)$ was removed from flasks supplemented with PCP-MS and hexadecane (1\%), and PCP concentration decreased $10 \%$ (50 mg. ${ }^{-1}$ ) in MS flasks with PCP as sole source of carbon and energy. The interesting aspect of these tests is the fact that hexadecane is a persistent contaminant of the environment.

The rationale behind these experiences is to evaluate the degradability of lower chlorinated phenols, because these contaminants may appear as by-products of the production of PCP (Middaugh et al., 1993). Using these as co-substrates in the field might be beneficial to increase the rate of PCP degradation, giving the PCP degraders an advantage over the native flora, which tolerate the phenols but do not degrade it. This is an approach that differs from the classical use of readily degradable co-substrates such as glucose or carbohydraterich residues (Papanastasiou, 1982; Rozich and Colvin, 1986; Premalatha and Rajakumar, 1994 and Topp et al., 1988; Hendriksen et al., 1992).

The inhibitory effect of PCP is known, even to those microorganisms capable of degrading it (Ruckdeschel et al., 1987). We tested the inhibitory effect measuring the viable cell concentration as $\mathrm{CFU} / \mathrm{ml}$ (Colony Forming Units per $\mathrm{ml}$ ) after two hours of inoculating PCP to a mixed culture medium and recording the rate of PCP disappearance (absorbance at $320 \mathrm{~nm}$ ), since it has been shown that after PCP inoculation, the cultures may experience a severe decrease in viability (González, 1995). The specific degradation rate decreased within the range of concentrations studied (Fig. 3). This is in agreement with results of previous studies (González and $\mathrm{Hu}$, 1995; Shaw et al., 1997).

We have also shown that the degradation of PCP proceeds only with viable cells in the following experiment with flasks containing about $40 \mathrm{mg} \cdot \mathrm{I}^{-1}$ of PCP and sodium azide. The results shown in Fig. 4 indicate that both flasks with PCP and the enriched culture degraded initially the PCP, that the degradation of PCP in the second flask stopped the moment when azide was added (indicated 


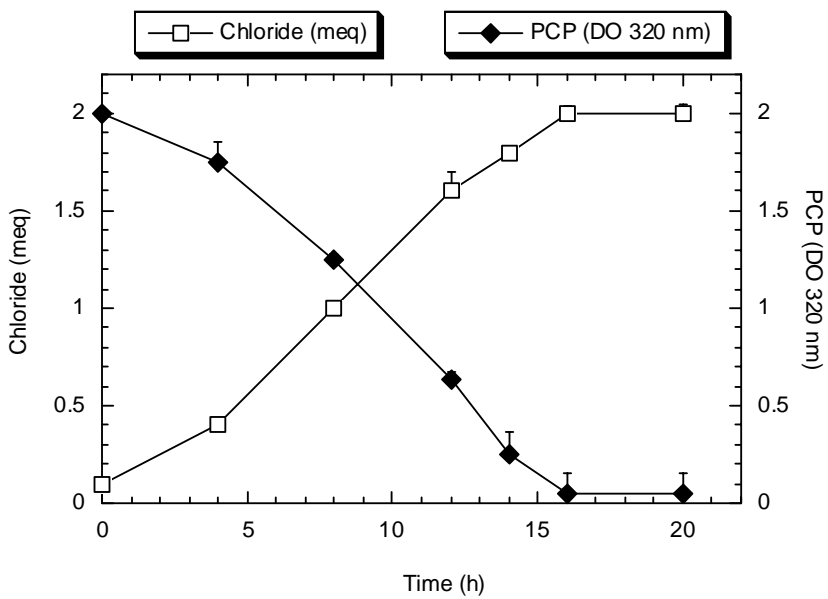

Figure 8

Release of inorganic chloride during growth of mixed population on $100 \mathrm{mg} \cdot \mathrm{l}^{-1}$ PCP (PCPAbs ${ }_{320}=1$ correspond to $\left.50 \mathrm{mg} \cdot \mathrm{l}^{-1}\right)$.

Symbols: • PCP concentration; $\square$, chloride concentration.

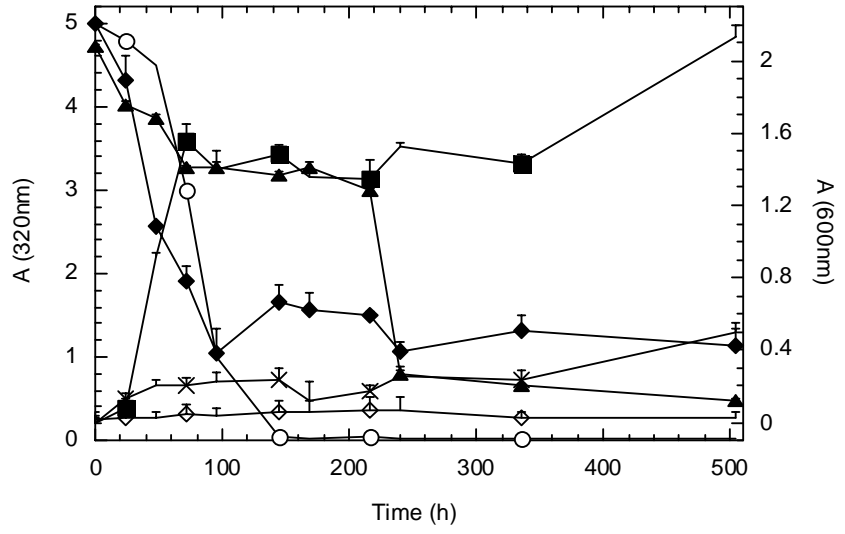

Figure 9

Effect of addition of $0.5 \%(\mathrm{~W} / \mathrm{V})$ glucose and $1 \%(\mathrm{~V} / \mathrm{V})$ hexadecane on degradation of PCP by mixed culture. PCP concentration was measured at $320 \mathrm{~nm}\left(P C P A b s_{320}=1\right.$ correspond to $50 \mathrm{mg}^{-1} \mathrm{l}^{-1}$ ) and biomass at $600 \mathrm{~nm}$. Symbols:

Glucose assay: $P C P$ concentration and -, biomass; hexadecane assay: $\mathbf{\Lambda}, P C P$ concentration and $\mathbf{X}$, biomass; assay with $P C P$ as sole source of carbon and energy: $\bigcirc, P C P$ concentration and $\diamond$, biomass.

by an arrow in the figure), and that the two flasks containing azide from the start did not show any PCP degradation. This is taken as an indication that the biodegradation of PCP proceeds biologically. In an additional check, the PCP degrading culture was cultivated in "low buffer" medium and bromothymol blue as indicator. As control flasks P. fluorescens 184 and E. coli 251:199 were cultivated in the same medium. Only the tubes with the PCP degrading culture coloured the medium yellow (due to the release of $\mathrm{Cl}^{-}$from $\mathrm{PCP}$ and the consequent formation of $\mathrm{HCl}$ ), while the others remained unchanged. An additional check for the degradation of PCP was made. The change in the chloride ion concentration (Fig. 8) flasks containing MS medium plus $100 \mathrm{mgPCP} \mathrm{I}^{-1}$, inoculated with the mixed culture for one week until complete disappearance of the absorbance peak at $320 \mathrm{~nm}$, were measured. The increase in $\mathrm{Cl}^{-}$ion concentration in the medium represented $100 \%$ of the $\mathrm{Cl}^{-}$liberated by complete degradation of the PCP.

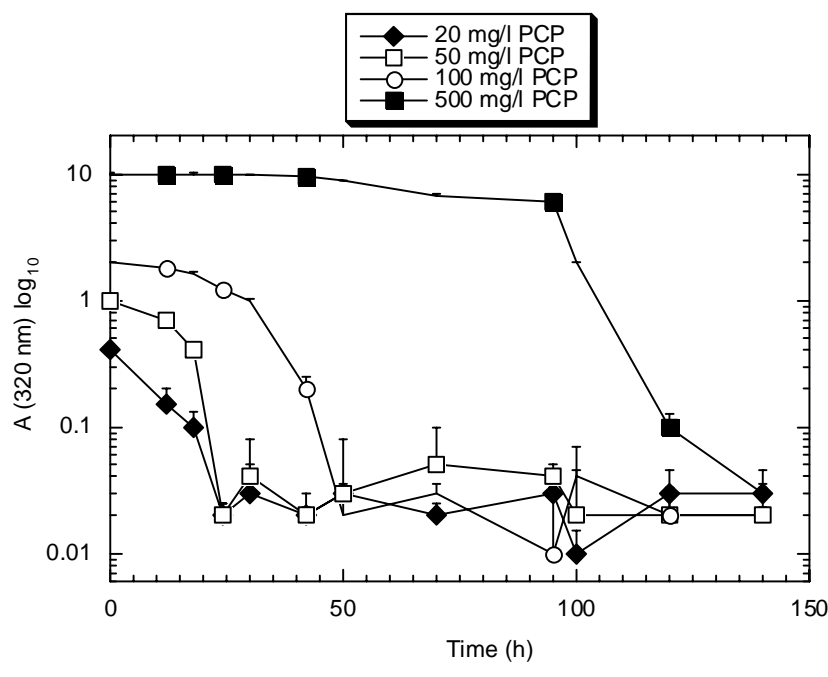

Figure 10

PCP removal at different concentration in PCP-MS batch Erlenmeyer flasks by mixed population. PCP as sole source of carbon and energy. PCP concentration was measured at 320 $\mathrm{nm}\left(\mathrm{PCPAbs}_{320}=1\right.$ correspond to $\left.50 \mathrm{mg} \cdot \mathrm{I}^{-1}\right)$. PCP concentration: - $20 \mathrm{mg} \cdot \mathrm{I}^{-1} ; \square, 50 \mathrm{mg} \cdot \mathrm{I}^{-1}$; $\mathrm{O}, 100 \mathrm{mg} \cdot \mathrm{I}^{-1}$ and $\mathbf{- 1}, 500 \mathrm{mg} \cdot \mathrm{I}^{-1}$

\section{Pure culture experiments}

Several strains were isolated from the mixed culture mentioned in the previous section, but only a minor fraction proved to be PCP degraders. Those capable of degrading the $\mathrm{PCP}$ were re-tested in their specific PCP consumption rate as described previously. Two of these strains were selected for further experiments. We evaluated the growth and degradation capacity of two strains, coded $\mathrm{H}$ and $\mathrm{B}$, with PCP in presence and absence of glucose.

The results are summarised in Figs. 5 and 6, where it can be seen their different behaviour specially after having grown in glucose: although both were isolated from plates with PCP as the only carbon source, the PCP degrading ability of strain B is at least severely impaired when re-grown in medium containing only PCP. Such capability is easily recovered by strain $B$ with the addition of $\mathrm{PCP}$ plus glucose. In contrast, strain $\mathrm{H}$ is capable of degrading and growing in the presence of $\mathrm{PCP}$ alone. That is, strain $\mathrm{B}$ seems to be dependent on an ancillary carbon source to keep its degrading capacity. This is consistent with other observations in which PCP degradation rates in several effluents and soils correlated with the organic matter content (Rozich and Colvin, 1986; Topp et al., 1988; González and Hu, 1991; McAllister et al., 1996).

\section{Preliminary strain identification}

By means of gas-chromatography analysis of the cell membrane lipids, strain $\mathrm{H}$ has been preliminary identified as Pseudomonas aeruginosa and strain B as Alcaligenes or Bordetella. Strain B is possibly a novel PCP degrader. Confirmatory experiments will need to be carried out using molecular biology techniques.

\section{Conclusions}

Our study showed that it is possible to isolate and enrich microbial consortia capable of degrading hexadecane, phenol, pentachlorophenol and lower chlorinated phenols. The above results suggest the feasibility of the use of toxic chemicals as phenols, hexadecane and other chlorophenols as co-substrates in field decontamination 
processes. This is the first report to mention the concomitant degradation of PCP and hexadecane by a mixed population. Results suggest that PCP degradation by mixed population is not subject to glucose or hexadecane repression. When supplemented with glucose, in contrast to Shaw et al (1997), our results showed that Pseudomonas aeruginosa and the possible novel Achromobacter or Bordetella sp. grew during and subsequent to PCP degradation.

The persistence (probably due to its toxicity to the degraders) of one isomer 2,4,5 TCP has been demonstrated as in other reports as well (Leeet al., 1998). Work performed on the toxic waste component phenol showed that, even after extensive acclimation, heterogeneous populations demonstrated inhibitory growth kinetics with further increases in substrate concentration (Rozich and Colvin, 1986). Because of these radically different growth rate characteristics, it is prudent to determine if some form of substrate interaction could be expected when toxic and nontoxic carbon sources are concurrently available to microbial populations. The isolation of pure strains from such a consortium has also been achieved, its PCP degradation ability confirmed, and the different effects of glucose on their degrading capacity have been shown. Preliminary identification of these strains has been carried out and further work continues on their characterisation. More research is necessary to understand the fundamental mechanisms of enhancement and inhibition in the microbial degradation of superhigh concentration of toxic compounds. However, this micro-organism could be used very effectively for in situ bioremediation in an environment which is highly contaminated with PCP, other chlorinated phenols and hexadecane. Since $P$. aeruginosa is an opportunistic pathogen, the characterisation of the appropiate genes to construct improved strains with enhanced degradation ability will need to be carried out.

\section{Acknowledgments}

Support was given by the ANPCyT, Argentina (Grant 13-03246) and the Universidad Nacional de Mar del Plata. S. Murialdo wishes to thank CONICET, Argentina for his fellowship. Thanks are also given to C. Studdert, I.I.B (Instituto de Investigaciones Biológicas), H. Asencio, J. Cechini, F Ivorra and C. Rodríguez for their kind cooperation.

\section{References}

APAJALAHTI JHA and SALKINOJA-SALONEN MS (1986) Degradation of polychlorinated phenols by Rhodococcus chlorophenolicus. Appl. Microbiol. Biotechnol. 25 62-67.

BAKER MD, MAYFIELD CI and INNISS WE (1980) Degradation of chlorophenols in soil, sediment and water at low temperature. Water Res. 14 1765-1771.

BOLLAG JM, HELLING CS and ALEXANDER MJ (1986) 2,4-D metabolism. Enzymatic hydroxylation of chlorinated phenols. J. Agric. Food Chem. 16 826-828.

BORTHWICK PW and SCHIMMEL SC (1978) Toxicity of pentachlorophenol and related compounds to early life stages of selected estuarine animals. In: K Ranga Rao (ed.) Pentachlorophenol: Chemistry, Pharmacology and Environmental Technology, Plenum Press, New York.

CHU J and KIRSCH EJ (1973) Utilization of halophenols by a pentachlorophenol metabolizing bacterium. Dev. Ind. Micro. 14 264-263.

COLORES GM, RADEHAUS PM and SCHMIDT SK (1995) Use of pentachlorophenol degrading bacterium to bioremediate highly contaminated soil. Appl. Biochem. and Biotechnol. 54 271-275.

CORTÉS D, GARRIOS-GONZÁLEZ J and TOMASINI A (2002) Pentachlorophenol tolerance and removal by Rhizopus nigricans in solidstate culture. Proc. Biochem. 37 881-884.
DRAHONOVSKY J and VACEK Z (1971) Dissoziationkonstanten und austauscherchromatographie chlorierter phenole. Collection Czechoslov. Chem. Commun. 36 3431-3440.

FRANSON MAH (1998) (ed.) Standard Methods For the Examination of Water and Wastewater. APHA, Washington, DC.

GONZÁLEZ JF (1995) Pentachlorophenol Degradation by a Flavobacterium sp. and its Application to Soil Decontamination. Ph.D. Thesis, Univ. of Minnesota, Minneapolis, USA.

GONZÁLEZ JF and HU WS (1991) Effect of glutamate on the pentachlorophenol degradation by a Flavobacterium sp. Appl. Microbiol. and Biotechnol. 35 100-104.

GONZÁLEZ JF and HU WS (1995) PCP degradation by a Flavobacterium sp. Simple Models. Environ. Technol. 16 287-292.

HAGGBLOM MM and VALO RJ (1995) Bioremediation of chlorophenol wastes. In: Wiley-Liss (ed.) Microbial Transformation and Degradation of Toxic Organic Chemicals, NJ. 389-434.

HENDRIKSEN V, LARSEN S and AHRING BK (1992) Influence of a supplemental carbon source on anaerobic dechlorination of pentachlorophenol in granular sludge. Appl. and Environ. Microbiol. 58 (1) 365-370.

KEITHER LH and TELLARD WA (1979) Priority pollutants. A perspective view. Environ. Sci. Technol. 13 416-423.

KIRSCH EJ and ETZEL JE (1973) Microbial decomposition of pentachlorophenol. J. Water Pollut. Control. Fed. 45 359-364.

KLECKA GM and MAIER WJ (1985) Kinetics of Microbial growth on pentachlorophenol. Appl. Environ. Microbiol. 49 46-53.

LEE S-G, YOON B-D, PARK Y-H and OH H-M (1998) Isolation of a novel pentachlorophenol-degrading bacterium, Pseudomonas sp. Bu 34. J. of Appl. Microbiol. 85 1-8.

LIU D, THOMSON K and STRACHAN WMJ (1981) Biodegradation of pentachlorophenol in a simulated aquatic environment. Bull. Environ. Contam. Toxicol. 26 85-90.

McALLISTER KA, HUNG L and TREVORS JT (1996) Microbial degradation of pentachlorophenol. Biodegr. 7 1-7.

McBAIN A, CUI F, HERBERT L and RUDDICK JNR (1995) The microbial degradation of chlorophenolic preservatives in spent pressure-treated timber. Biodegr. 6 47-55.

MIDDAUGH DP, Resnick SM, Lantz SE, Heard CS and Mueller JG (1993) Toxicological assessment of biodegraded pentachlorophenol: Microtox and fish embryos. Arch. Environ. Contam. Toxicol. 24 165-172.

MOOS LP, KIRSCH EJ, WUKASCH RF and GRADY CPL (1983) Pentachlorophenol biodegradation. Water Res. 17 1575-1584.

NEILSON AH, ALLARD AS and REMBERGER M (1985) Biodegradation and transformation of recalcitrant compounds. In: $\mathrm{O}$ Hutzinger (ed.) The Handbook Of Environmental Chemistry Vol 2, part C. Springer-Verlag KG. Berlin. 29-86.

PAPANASTASIOU AC (1982) Kinetic of biodegradation of 2,4dichlorophenoxy-acetate in the presence of glucose. Biotechnol. and Bioeng. 24 2001-2011.

PIGNATELLO JJ, MARTINSON MM, STEIERT JG, CARLSON RE and CRAWFORD RL (1983) Biodegradation and photolysis of pentachlorophenol in artificial freshwater streams. Appl. and Environ. Microbiol.. 46 1024-1031.

PREMALATHA A and RAJAKUMAR GS (1994) Pentachlorophenol degradation by Pseudomona aeruginosa. World J. Microbiol. and Biotechnol. 10 334-337.

PUHAKKA JA, HERWIG RP, KORO PM, WOLFE GV and FERGUSON JF (1995) Biodegradation of chlorophenols by mixed and pure cultures from a fluidized-bed reactor. Appl. Microbiol. Biotechnol. 42 951-957.

RADEHAUS PM and SCHMIDT SK (1992) Characterization of a novel Pseudomonas sp. that mineralizes high concentrations of pentachlorophenol. Appl. Environ. Microbiol. 58 (9) 2879-2885.

RAMOS JL, DUQUE E, HUERTAS MJ and HAISOUR A (1995) Isolation and expansion of the catabolic potential of a Pseudomonas putida strain able to grow in the presence of high concentrations of aromatic hydrocarbons. J. Bacteriol. 177 3911-3916.

REDDY GVB and GOLD MH (2000) Degradation of pentachlorophenol by Phanerochaete chrysosporium: Intermediates and reactions involved. Microbiol. 146 405-413. 
RESNICK SM and CHAPMAN PJ (1994) Physiological properties and substrate specificity of a pentachlorophenol-degrading Pseudomonas species. Biodegr. 5 47-54.

ROZICH AF and COLVIN RJ (1986) Effects of glucose on phenol biodegradation by heterogeneous populations. Biotechnol. and Bioeng. 28 965-971.

RUCKDESCHEL G, RENNER G and SCHWARZ K (1987) Effects of pentachlorophenol and some of its known and possible metabolites on different species of bacteria. Appl. and Environ. Microbiol. 53 (11) 2689-2692.

SABER DL and CRAWFORD RL (1985) Isolation and characterization of Flavobacterium strains that degrade pentachlorophenol. Appl. and Environ. Microbiol. 50 (6) 1512-1518.

SCHENK T, MULLER R, MORSBERGER F, OTTO MK and LINGENS F (1989) Enzymatic dehalogenation of pentachlorophenol by extracts from Arthrobacter sp. Strain ATCC 33790. J. Bacteriol. $1715487-5491$

SHAW KW, LEE H and TREVORS J (1997) Effect of initial cell density, substrate concentration and temperature on pentachlorophenol degradation by Pseudomonas sp. J. Chem. Technol. Biotechnol. 69 107-113.
SITTIG M (1981) Handbook of Toxic and Hazardous Chemicals, Noyes Publications, Park Ridge, NJ.

STANLAKE GJ and FINN RK (1982) Isolation and characterization of a pentachlorophenol-degrading bacterium. Appl. Environ. Microbiol. 44 1421-1427.

STEIERT JG, PIGNATELLO JJ and CRAWFORD RL (1987) Degradation of chlorinated phenols by a pentachlorophenol degrading bacterium. Appl. Environ. Microbiol. 53 907-910.

STEIERT JG, THOMA WJ, UGURBIL K and CRAWFORD RL (1988) Nuclear magnetic resonance studies of effects of some chlorophenols on Escherichia coli and a pentachlorophenol degrading bacterium. J. Bacteriol. 170 4954-4957.

TOPP E, CRAWFORD RL and HANSON RS (1988) Influence of readily metabolizable carbon on pentachlorophenol metabolism by a pentachlorophenol-degrading Flavobacterium sp. Appl. and Environ. Microbiol. 54 2452-2459.

TUOMELA M, LYYTIKAINEN M, OIVANEN P and HATAKKA A (1999) Mineralization and conversion of pentachlorophenol (PCP) in soil inoculated with the white-rot fungus Trametes versicolor. Soil Biol. and Biochem. 31 65-74. 
